\title{
The Impact of Voice Disorders Among Teachers: Vocal Complaints, Treatment-Seeking Behavior, Knowledge of Vocal Care, and Voice-Related Absenteeism
}

\author{
*Evelyne Van Houtte, *Sofie Claeys, tFloris Wuyts, and ¥Kristiane Van Lierde, ${ }_{\ddagger}^{\ddagger}$ Ghent and $\dagger$ Antwerp, Belgium
}

\begin{abstract}
Summary: Objectives. Teachers are at increased risk for developing voice disorders. Occupational risk factors have been extensively examined; however, little attention has been paid to the consequences of the vocal complaints. The objective of this study was to investigate the knowledge that teachers have about vocal care, treatment-seeking behavior, and voice-related absenteeism.

Methods. The study group comprised 994 teachers and 290 controls whose jobs did not involve vocal effort. All participants completed a questionnaire inquiring about vocal complaints, treatment-seeking behavior, voice-related absenteeism, and knowledge about vocal care. Comparisons were made between teachers with and without vocal complaints and with the control group.

Results. Teachers reported significantly more voice problems than the control population $(51.2 \%$ vs $27.4 \%)$ $\left(\chi^{2}=50.45, \mathrm{df}=1, P<0.001\right)$. Female teachers reported significantly higher levels of voice disorders than their male colleagues $\left(38 \%\right.$ vs $\left.13.2 \%, \chi^{2}=22.34, \mathrm{df}=1, P<0.001\right)$. Teachers $(25.4 \%)$ sought medical care and eventually $20.6 \%$ had missed at least 1 day of work because of voice problems. Female teachers were significantly more likely to seek medical help $\left(\chi^{2}=7.24, \mathrm{df}=1, P=0.007\right)$ and to stay at home $\left(\chi^{2}=7.10, \mathrm{df}=1, P=0.008\right)$ in comparison with their male colleagues. Only $13.5 \%$ of all teachers received information during their education.

Conclusions. Voice disorders have an impact on teachers' personal and professional life and imply a major financial burden for society. A substantial number of teachers needed medical help and was obligated to stay at home because of voice problems. This study strongly recommends the implementation of vocal education during the training of teacher students to prepare the vocal professional user.
\end{abstract}

Key Words: Teachers-Voice disorders-Voice-related occupational disease.

\section{INTRODUCTION}

Professional voice users, especially teachers, have been found to be at increased risk for voice disorders. ${ }^{1-3} \mathrm{~A}$ number of studies have focused on the teaching population and showed that the prevalence of vocal dysfunction was significantly higher in teachers (ranging from $11 \%$ to $81.0 \%$ ) compared with nonteachers (ranging from $1.0 \%$ to $36.1 \%$ ). ${ }^{1,4-11}$ This high prevalence is because of intense and prolonged occupational voice use, speaking in a noisy environment, and inefficient phonation techniques. Teachers are more susceptible to aphonia, edema, polyps, and nodules than nonvocal professionals. ${ }^{5-7,12}$ Vocal dysfunction leads to a lesser quality of teaching, an increased absenteeism, and a major financial burden. Serious personal and emotional consequences may also result for the individual teacher. Teachers feel limited in their current job performances and in their future job or career options because of their voice problems. ${ }^{6}$

Therefore, a large number of studies have focused on occupational vocal risk factors. Years of teaching have been identified as a risk factor because of cumulative voice use. ${ }^{13,14}$ The

\footnotetext{
Accepted for publication April 21, 2010.

From the *Department of Otolaryngology and Head and Neck Surgery, University Hospital Ghent, Belgium; †Antwerp University Research Center for Equilibrium and Aerospace, Department of ENT, Antwerp, Belgium; and the †ेDepartment of Otolaryngology, University Hospital Ghent, Belgium.

Address correspondence and reprint requests to Evelyne Van Houtte, Universitair Ziekenhuis Gent, Neus-, keel- en oorheelkunde 1P1, De Pintelaan 185, 9000 Ghent, Belgium. E-mail: Evelyne.vanhoutte@ugent.be

Journal of Voice, Vol. 25, No. 5, pp. 570-575

0892-1997/\$36.00

(C) 2011 The Voice Foundation

doi:10.1016/j.jvoice.2010.04.008
}

number of pupils in the classroom also showed to be important since teaching a larger group requires more vocal effort. ${ }^{13}$ Abundant background noise or classrooms with bad acoustics forces the teacher to speak more loudly, which also increases the risk. ${ }^{9}$ Other unfavorable working conditions, for example, dry air, dust, smoke, temperature changes, may irritate the mucosa and negatively influence the voice. ${ }^{15}$

Psychoemotional factors and stress have been consistently shown to be related to voice disorders. ${ }^{5,8,13}$ Emotions can influence voice production negatively, especially in sensitive persons. Increase in stress changes the phonation pattern with a subsequent increase in voice load. ${ }^{8,16}$

In contrast to the elaborate literature describing the vocal risk factors, little attention has been paid to the consequences of these voice disorders. Vocal dysfunction may lead to extensive periods of sick leave and vocal rehabilitation, whether or not combined with surgical intervention, which involves great financial costs. Few studies have investigated the treatmentseeking behavior of the teachers or voice-related absenteeism. Moreover, there is a lack of research examining whether teachers received information during their training or during their career about the physiology of their voice, vocal techniques, and the use of vocal hygiene.

The purpose of this study was to provide an in-depth analysis of different aspects regarding the impact of voice disorders in professional voice users: (1) the knowledge of teachers concerning vocal car; (2) their treatment-seeking behavior; and (3) the duration of the voice-related absenteeism. This study contributes to the knowledge of the development of voice disorders in teachers and helps to further develop preventive 
programs to reduce the impact and severity of voice problems in teachers.

\section{METHODS}

\section{Description of the questionnaire}

The questionnaire of this study was based on existing questionnaires in the literature, ${ }^{4-6,8-10,13,15}$ the investigators' clinical experience, and suggestions from teachers. The outcome variable was "Have you ever had a voice disorder during your professional career?" Voice disorder was defined as any time the voice did not work, perform, or sound as it usually does and interfered with communication. The survey addressed four main categories: (1) Ear, nose and throat (ENT), vocal and corporal complaints; (2) treatment-seeking behavior; (3) voice-related absenteeism; and (4) knowledge concerning vocal care. Specific questions elicited information regarding (1) ENT symptoms: nasal obstruction, dry nose, rhinorrhea, postnasal drip; (2) vocal complaints: hoarseness, a tired voice, loss of voice, loss of voice control, loss of voice range, pain after speaking, globus sensation, dry mouth at day, dry mouth at night, dry mouth when speaking; (3) corporal complaints: headache, sore throat, neck pain; (4) the frequency and type of consulted physician; (5) the need and duration of voice therapy; (6) the prevalence of voice-related absenteeism; (7) the specific duration of the sick leave; (8) source of information regarding vocal care; and (9) use of vocal hygiene rules. Demographic variables considered in this study were age and gender.

The questionnaire was accompanied by a description of the background and the aim of the study. Teachers were asked to score their ENT symptoms, vocal complaints, and physical discomfort using a visual analog scale (VAS). ${ }^{17}$ This scale measures $10 \mathrm{~cm}$ and ranged from " 0 as no complaints" in one end to " 10 as extremely severe" at the other end. Teachers were asked to mark the line where they experienced their problems. Treatment-seeking behavior and knowledge of vocal care were interrogated with yes/no questions.

\section{Sampling procedures}

The questionnaires were distributed between October 2008 and June 2009. Randomly selected schools in the provinces of the Flanders (the Northern Flemish part of Belgium) were chosen from a list provided by the Web site of the State Office of Education. Every educational level and type was included: kindergarten schools, elementary schools, and high schools. An equal number of schools in the cities as in the suburbs were selected. The teachers aged between 21 and 65 years (mean age $=38.9$ years). The initial contact was made by telephone to the principal of the school. The purpose of the study was briefly explained, and the school was asked to participate. If the principal agreed, a questionnaire for every teacher was passed to the school and distributed by the principal. It was the teachers' own choice to complete the survey or not. The questionnaires were again collected by the investigators of the study. When a school would not participate, the main reason was that the teachers were already overloaded with questionnaires and the workload was too heavy. In total,
2133 questionnaires were delivered at the schools and 994 were available for analysis. The response rate for the teacher group was 46.6\% (994/2133).

The control population was sampled by a mailing list of all employees of the University of Ghent. This sample consisted of working individuals in occupations with low vocal loading (administrators, secretaries, research workers, information and communication technology (ICT) personnel, technicians, social workers, nurse/health aides, etc) of the same geographic area and age criteria (21-65 years, mean 36.5 years). None of the controls had ever participated in any form of teaching. The questionnaires were emailed to all employees and, once completed, emailed back to the investigators. A total number of 290 questionnaires were returned.

\section{Statistical methods}

All data were evaluated using the statistical program SPSS version 18 (SPSS Inc., Chicago, IL). The relationships between voice disorders that occurred at any time and various factors were assessed. Nonparametric data were treated with the Mann-Whitney $U$ test for comparison between groups. Logistic regression and multiple linear regression methods were used to predict outcome based on a combination of multiple factors. Logistic regression models were simultaneously adjusted for gender. Chi-square tests were used to investigate association between groups for the occurrence of one or more characteristics. In all statistical tests, two-tailed tests of significance and confidence intervals were based on the level of $P<0.05$. Comparisons were made between teachers with and without voice complaints and between the teacher group and the control population.

\section{RESULTS}

\section{Profile of the participants}

In total, 994 teachers completed the questionnaire. The overall response rate was $46.6 \%(994 / 2133)$. The teacher group consisted of $67.4 \%(n=670 / 994)$ females and $32.6 \%(n=324 /$ 994) males. The mean age of the teachers was 38.9 years (range 21-65 years). The greatest number of the teachers worked at the secondary school level $(69.6 \%, 690 / 994)$. Teachers working in primary schools accounted for $23.5 \%$ (233/994) and in kindergarten for 6.9\% (68/994). The largest group (25.6\%, 254/994) had been teaching for 1 to 5 years. The second largest group $(19.8 \%, 197 / 994)$ had been teaching for 25 to 30 years. In the group of teachers, more than half of them $(n=509 / 994$, $51.2 \%$ ) had suffered from vocal complaints at some point during their career as a teacher. Female teachers suffered significantly more often than their male colleagues as depicted in Figure $1\left(38 \%\right.$ [378/994] vs $13.2 \%$ [131/994], $\chi^{2}=22.34$, $\mathrm{df}=1, P<0.001)$. In male teachers, the prevalence of reporting a voice disorder was significantly related with age $\left(\chi^{2}=11.24\right.$, $\mathrm{df}=3, P=0.010)$, whereas in women no age-related significance was found $\left(\chi^{2}=3.31\right.$, df $=3, P=0.347$ ).

The control population consisted of $71 \%(n=206 / 290)$ women and $29 \%(\mathrm{n}=84 / 290)$ men. The mean age was 36.5 years (range 18-68 years). Voice disorders occurred in $27.6 \%$ 


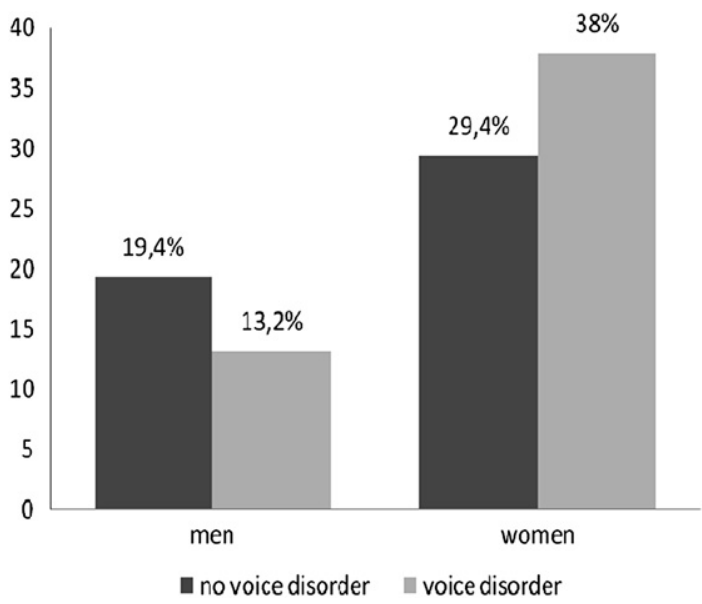

FIGURE 1. Percentages of voice disorders in the teacher group that consisted of $67.4 \%$ females and $32.6 \%$ males. Female teachers suffered significantly more of voice disorders compared with their male colleagues ( $38 \%$ vs $13.2 \%)$.

(80/290) in the control population. The prevalence was not significantly higher for females $(21.4 \%, 62 / 290)$ than males $(6.2 \%$, $18 / 290)\left(\chi^{2}=2.25, \mathrm{df}=1, P=0.134\right)$. The prevalence of voice disorders reported by teachers was significantly higher than in the control population $\left(\chi^{2}=50.45, \mathrm{df}=1, P<0.001\right)$.

\section{Voice-related complaints}

By means of a forward logistic regression, we were able to estimate the relative importance of different VAS characteristics that were necessary to discriminate healthy from dysphonic subjects. The following VAS characteristics were used as independent variables: (1) ENT symptoms: nasal obstruction, dry nose, rhinorrhea, postnasal drip; (2) vocal complaints: hoarseness, a tired voice, loss of voice, loss of voice control, loss of voice range, pain after speaking, globus sensation, dry mouth at day, dry mouth at night, dry mouth when speaking; (3) corporal complaints: headache, sore throat, neck pain; and (4) gender. Finally, using a linear combination of the VAS characteristics (hoarseness, a tired voice, loss of voice, loss of voice range, and gender), a correct classification of teachers with voice disorders could be achieved in total 73\% (726/ 994) of all subjects, with specificity of $81 \%$ and sensitivity of $66 \%$. By itself, this is not the aim of the analysis, but this method provides a tool to assess the relative importance of each individual variable as essential for the status dysphonic or healthy. As such, the most determining symptoms were (1) hoarseness; (2) loss of voice; and (3) diminished pitch and intensity with $\operatorname{Exp}(\mathrm{B})$ of $1.26,1.23$, and 1.19, respectively. Also, gender was part of the finally determining factors, with the result that men had less problems with their voice than women. These values correspond to the change in odds of having dysphonia in case of an increase with $1 \mathrm{~cm}$ on the VAS of the different characteristics (Table 1).

\section{Treatment-seeking behavior}

Table 2 illustrates the treatment-seeking behavior of the teachers. Of the 994 teachers, $253(25.4 \%, \mathrm{n}=253 / 994)$ sought medical help. Of the teachers with voice disorders $(n=509)$, this accounted for $49.7 \%$ (253/509). This was not significantly higher than the control group, which consulted a doctor in $43.7 \%(35 / 80)\left(\chi^{2}=0.98, \mathrm{df}=1, P=0.322\right)$ in case of vocal dysfunction. Among the teachers, the general practitioner $(26.2 \%, 135 / 509)$ was the most frequented physician followed by the otolaryngologist $(23 \%, 117 / 509)$. Table 2 shows that 28 teachers directly consulted an ENT specialist, whereas 86 were referred to a specialist after consulting the family doctor. The school physician was only frequented by two teachers. The treatment-seeking behavior among teachers was strongly related to (1) gender: women consulted significantly more (49.5\% vs $\left.35.9 \%, \chi^{2}=7.24, \mathrm{df}=1, P=0.007\right)$ than their male colleagues; $(2)$ the years of teaching $\left(\chi^{2}=4.38, \mathrm{df}=1\right.$, $P=0.036$ for men and $\chi^{2}=14.62, \mathrm{df}=1, P<0.001$ for women); (3) the age of the teacher $\left(\chi^{2}=3.85, \mathrm{df}=1\right.$, $P=0.05$ for men and $\chi^{2}=8.52$, df $=1, P=0.004$ for women); and (4) type of school. Kindergarten and primary school teachers consulted significantly more than the teachers of secondary school $\left(\chi^{2}=8.56, \mathrm{df}=2, P=0.014\right)$. Gender was not a determinant in the choice of the physician (general practitioner vs ENT specialist). Teachers who reported a greater severity of vocal complaints (hoarseness, vocal fatigue, loss of voice and voice range, diminished voice range, and pain in the throat after speaking) were significantly more likely to consult a doctor (all Mann-Whitney $U$ tests were significant at $P<0.001)$.

\section{Voice-related absenteeism}

Teachers experienced a significant higher number of days in their career in which they missed work because of their voice

TABLE 1.

Exp(B) of the Most Relevant Vocal Complaints and Gender as Determined by a Forward Logistic Regression

\begin{tabular}{|c|c|c|c|c|}
\hline \multirow[b]{2}{*}{ Vocal Complaint } & \multirow[b]{2}{*}{ Significance } & \multirow[b]{2}{*}{$\operatorname{Exp}(B)$} & \multicolumn{2}{|c|}{$\begin{array}{l}\text { 95\% Confidence } \\
\text { Interval for } \operatorname{Exp}(B)\end{array}$} \\
\hline & & & Lower & Upper \\
\hline Tired voice & 0.004 & 1.162 & 1.049 & 1.286 \\
\hline Loss of voice & 0.002 & 1.231 & 1.081 & 1.402 \\
\hline Loss of voice range & 0.002 & 1.190 & 1.066 & 1.328 \\
\hline
\end{tabular}


TABLE 2.

Treatment-Seeking Behavior of the Teachers

\begin{tabular}{lcc}
\hline Type of Medical Care & Frequency $(\mathrm{n})$ & Percent $(\%)$ \\
\hline No medical care & 739 & 74.3 \\
SD & 1 & 0.1 \\
GP & 135 & 13.6 \\
ENT specialist & 28 & 2.8 \\
SD + ENT & 1 & 0.1 \\
GP + ENT & 86 & 8.7 \\
GP + SD + ENT & 2 & 0.2 \\
Total & 992 & 99.8 \\
Missing & 2 & 0.2 \\
Total & 994 & 100.0 \\
\hline
\end{tabular}

Abbreviations: SD, school doctor; GP, general practitioner; ENT, ear, nose and throat.

in comparison with the control population $\left(\chi^{2}=24.97, \mathrm{df}=1\right.$, $P<0.001)$. More precisely, one out of five $(19.2 \%, 191 / 994)$ teachers reported missing at least 1 day of work because of voice-related dysfunction. In the general population, significantly fewer participants $(7.6 \%, 22 / 290)$ were absent from work because of voice problems. In the group of teachers with voice disorders, this accounted for 37.6\% (191/509). Figure 2 shows the duration of the absenteeism in teachers with voice disorders at any point during their career: $34.6 \%$ (66/191) missed 1 day at work, 20.4\% (39/191) missed several times 1 day, and $29.3 \%(56 / 191)$ missed 1 week. A substantial part of the teachers $(15.7 \%, 30 / 509)$ had to stay home for a longer period: $4.7 \%$ (9/191) missed 2 weeks, $6.8 \%$ (13/191) missed more than 2 weeks' work, and $4.3 \%$ (8/191) were not able to work repeatedly 1 week. Female teachers stayed significantly more often at home $\left(38.9 \%\right.$ vs $26 \%, \chi^{2}=7.10, \mathrm{df}=1$, $P=0.008)$ than male teachers.

\section{Voice therapy}

During their career, $51(5.1 \%, 51 / 994)$ teachers received voice therapy in comparison with $2.1 \%(6 / 290)$ in the general population $(P=0.316)$. For the majority $(n=28 / 51)$, a therapy of maximum 6 months was sufficient. Thirteen of the 51 teachers needed a treatment of 6 months to 1 year and 10 teachers need

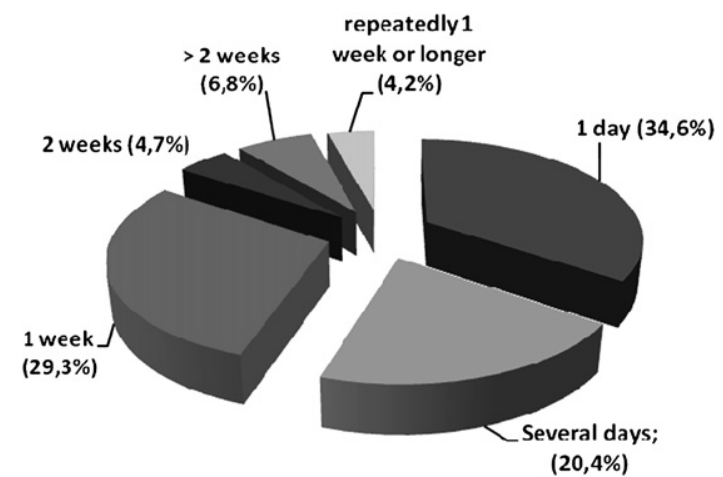

FIGURE 2. Duration of voice-related absenteeism in teachers with voice disorders at any point during their career. treatment for more than 1 year. Statistical analysis showed that teachers who had a voice disorder as a child or young adult and received voice therapy for this problem were not at an increased risk of developing a voice disorder further on in their career $\left(\chi^{2}=2.64, \mathrm{df}=2, P=0.267\right)$.

\section{Knowledge about vocal care among teachers}

Only 27.8\% (276/994) of the teachers received information about vocal hygiene and vocal techniques. For $13.5 \%$ (134/ 994) of the teachers, this was during their education to be a teacher. An even smaller number of teachers received information about vocal care during extra training or collected information at own initiative (Table 3). No gender-related differences were found among the teachers who collected information at own initiative. Unfortunately, the association between receiving information during the education and the prevention of voice problems later on in the career was not significant $\left(\chi^{2}=1.00, \mathrm{df}=1, P=0.317\right)$. When teachers were confronted with a voice problem, there was a need for information and significantly more teachers gathered information themselves $\left(\chi^{2}=15.78, \mathrm{df}=1, P<0.001\right)$ in comparison with their colleagues without voice disorders.

The survey examined whether teachers used their knowledge of vocal care in their everyday teaching. The aspects of vocal use and vocal hygiene teachers are most familiar with (1) increasing fluid intake; (2) trying to shout less; and (3) trying to avoid speaking in a noisy environment. Only a very small fraction $(0.6 \%, 9 / 994)$ of the teachers had ever used voice amplification.

\section{DISCUSSION}

This study provides descriptive data on voice-related absenteeism, treatment-seeking behavior, and knowledge of vocal care in teachers in comparison with the general population. This survey intended to give an overview of the consequences of occupational voice problems. The results indicated that more than half of the teachers $(51.2 \%, 509 / 994)$ experienced a voice disorder during their career. This finding was significantly greater than the control population $(27.6 \%, 80 / 290)$. This confirms that teaching is a profession with very high vocal demands. ${ }^{15,16,18}$ This outcome was consistent with those of Roy et al, ${ }^{4}$ Thibeault et al,${ }^{14}$ and de Jong et al. ${ }^{11}$ Female teachers reported significantly more voice problems than their male colleagues $(38 \%$ vs $13.2 \%$ ). This has been consistently reported in previous studies $^{5,11,12,16}$ and has mainly been ascribed to physiological reasons. Women have shorter vocal folds and produce voice at a higher fundamental frequency. Consequently, there is less tissue mass to dampen a larger amount of vibrations. At the molecular level, women have less hyaluronic acid in the superficial layer of the lamina propria. Hyaluronic acid plays an important role in wound repair. Lower amounts of hyaluronic acid indicate that there is less protective tissue dampening and, therefore, a reduced wound-healing response. $^{19}$

Vocal risk factors in teachers have been the subject of elaborate research. Unfortunately, these findings are often 


\begin{tabular}{|c|c|c|}
\hline $\begin{array}{l}\text { Information Received } \\
\text { by the Teacher }\end{array}$ & $\begin{array}{l}\text { Frequency } \\
(\mathrm{n})\end{array}$ & $\begin{array}{c}\text { Percent } \\
(\%)\end{array}$ \\
\hline No information & 717 & 72.1 \\
\hline Information during education & 87 & 8.8 \\
\hline Information during extra training & 31 & 3.1 \\
\hline $\begin{array}{l}\text { Information during education } \\
\text { and extra training }\end{array}$ & 10 & 1.0 \\
\hline Information at own initiative & 85 & 8.6 \\
\hline $\begin{array}{l}\text { Information during education } \\
\text { and at own initiative }\end{array}$ & 26 & 2.6 \\
\hline $\begin{array}{l}\text { Information during extra training } \\
\text { and at own initiative }\end{array}$ & 26 & 2.6 \\
\hline $\begin{array}{l}\text { Information during education, } \\
\text { extra training, and at own } \\
\text { initiative }\end{array}$ & 11 & 1.1 \\
\hline Missing & 1 & 0.1 \\
\hline Total & 994 & 100.0 \\
\hline
\end{tabular}

inconsistent. Moreover, many risk factors (gender, age, type of school, years of teaching, etc) are often very difficult or even impossible to change. Therefore, attention should be focused on prevention by use of efficient vocal techniques and vocal hygiene training (such as avoid chalk, increase daily fluid intake, decrease alcohol and caffeine consumption, stop smoking, avoid yelling, etc). An inefficient phonation technique is one of the most important factors in the pathogenesis of occupational dysphonia. ${ }^{10}$ Previous studies documented that teachers are at greater risk of developing hyperfunctional voice problems. ${ }^{10,20,21}$ Inefficient voicing in heavy vocal users leads to rapid voice deterioration, development of functional and, later on, organic disorders adversely affecting their ability to work. $^{22,23}$ In this study, a cluster of voice-related symptoms (hoarseness, loss of voice, and loss of voice range) were consistently reported by dysphonic teachers and will presumably have implications for both the quality of teaching and the students' learning experience.

Half of the affected teachers sought medical help. This outcome was in high contrast with the finding of Roy et $\mathrm{al}^{4}$ and Russell et $\mathrm{al}^{5}$ who reported that $14.3 \%$ of the American and $32.7 \%$ of the Australian teacher consulted a doctor, respectively. Roy et $\mathrm{al}^{4}$ assumed that teachers were reluctant to take time off from work for medical appointments, or that they fear physician advice to reduce voice use or change occupations. Russell et $\mathrm{al}^{5}$ documented that $32.7 \%$ visited a doctor and stated that teachers view voice problems as occupational hazards and may not be aware of the help available to them. The higher prevalence in the present study could be explained by the growing awareness of vocal care or by the organization of the health system in Belgium. Consulting a physician is almost fully reimbursed in Belgium, and there is a low threshold for consulting a specialist (practically, no extra fee and no referring are necessary from the general practitioner). The physician plays an important role in supporting the teacher. Voice disorders have a major psychoemotional impact ${ }^{13,16,24}$ because they can threaten, shorten, or even end a teachers' career. Moreover, voice disorders have not been recognized as a professional disease, which makes it more stressful for the teacher to justify his/her sick leave. In cases of emotional distress, the family doctor is often the first aid. This was confirmed by the results of our survey because the general practitioner was the most frequented physician. It was striking that only a very limited fraction consulted the school doctor. In the future, physicians could play a crucial role in supporting the teachers, reducing the psychoemotional impact, and thereby decreasing the voice-related absenteeism. This survey also showed a strong relation between voice disorders and sick leave, $20.6 \%$ of the teachers with voice disorders had missed 1 or more days at work, which was significantly more than the general population. These results were similar to the results of Smith et al ${ }^{6}$ and Titze et al. ${ }^{2}$ In the vast majority, sick leave was limited to 1 week or less, but $16 \%$ of the teachers were absent for more than a week. Because teachers are a significant portion of the working population $(6.7 \%$ in the Flemish part of Belgium ${ }^{25}$ ), these data stress the important economic consequences because of sick leave, voice therapy, and/or surgical management.

Teachers were inquired about their knowledge related to vocal care. It appeared that only $27.4 \%$ of the teachers had received any kind of information. Only a small percentage $(13.5 \%)$ was taught during training. Because it is very difficult to identify or eliminate vocal risk factors, a good knowledge of vocal care could decrease the number of voice problems in teachers. Unfortunately, vocal care has not been taken up in the educational program. Based on this study, we argue for the implementation of a course about the physiology of the voice and vocal care in all teacher programs. The effectiveness of preventative strategies (such as vocal hygiene training and vocal function exercises) has already been documented by previous research. ${ }^{26-28}$ In this study, there was no association between receiving information during the education and the prevention of voice disorders. Courses should be devoted to presentation skills and public speaking. Issues related to the anatomy and physiology of the voice, reflux, medical management of the voice, and how these contribute to or detract from efficient voice use needs to be addressed. Moreover, maintaining and updating this knowledge through prevention programs in extra trainings during the teachers' career should be promoted. Focus should be on sensitizing professionals to voice problems so they can recognize the symptoms early. When teachers are informed about their voice, early detection and treatment could reduce voicerelated absenteeism and decrease the impact on the personal and social life of the teacher.

\section{CONCLUSION}

This study argues for the implementation of prevention programs. First, more than half of the teachers had to cope with a voice disorder at a certain point during their career. Second, 
one out of four teachers sought medical help for a voice problem. Third, one out of five teachers will eventually stay at home for 1 or more days because of a voice problem. Female teachers scored significantly higher on all three parameters in comparison with their male colleagues. In addition, women compile the largest group of the teachers, which represents a non-negligible portion of the working population. These three factors are responsible for a major financial burden that could partially diminish if the teaching about the physiology of the voice and vocal hygiene was introduced in the educational program. Personal characteristics, work-related voice load, and environmental risk factors have been extensively investigated but are difficult to identify and change frequently according to the conducted study. Therefore, they should not be the point of focus for the physician. Attention should be paid to efficient vocal techniques, vocal hygiene, and awareness of vocal care early in the education. The findings of this survey have important implications for the public health and strongly recommend the implementation of vocal education during the training of teacher students. In the future, there is a need for research focusing on the benefit of early prevention and intervention programs for teachers.

\section{REFERENCES}

1. Fritzell B. Voice disorders and occupations. Logoped Phoniatr Vocol. 1996; 21:7-12.

2. Titze IR, Lemke J, Montequin D. Populations in the U.S. workforce who rely on voice as a primary tool of trade: a preliminary report. $J$ Voice. 1997;11:254-259.

3. Roy N, Merrill RM, Thibeault S, Gray SD, Smith EM. Voice disorders in teachers and the general population: effects on work performance, attendance, and future career choices. J Speech Lang Hear Res. 2004;47:542-551.

4. Roy N, Merrill RM, Thibeault S, Parsa RA, Gray SD, Smith EM. Prevalence of voice disorders in teachers and the general population. J Speech Lang Hear Res. 2004;47:281-293.

5. Russell A, Oates J, Greenwood KM. Prevalence of voice problems in teachers. J Voice. 1998;12:467-479.

6. Smith E, Gray SD, Dove H, Kirchner L, Heras H. Frequency and effects of teachers' voice problems. J Voice. 1997;11:81-87.

7. Smith E, Kirchner HL, Taylor M, Hoffman H, Lemke JH. Voice problems among teachers: differences by gender and teaching characteristics. $J$ Voice. 1998;12:328-334.

8. Gotaas C, Starr CD. Vocal fatigue among teachers. Folia Phoniatr (Basel). 1993;45:120-129.

9. Sapir S, Keidar A, Mathers-Schmidt B. Vocal attrition in teachers: survey findings. Eur J Disord Commun. 1993;28:177-185.
10. Sliwinska-Kowalska M, Niebudek-Bogusz E, Fiszer M, Los-Spychalska T, Kotylo P, Sznurowska-Przygocka B, Modrzewska M. The prevalence and risk factors for occupational voice disorders in teachers. Folia Phoniatr Logop. 2006;58:85-101.

11. de Jong FI, Kooijman PG, Thomas G, Huinck WJ, Graamans K, Schutte HK. Epidemiology of voice problems in Dutch teachers. Folia Phoniatr Logop. 2006;58:186-198.

12. Smith E, Lemke J, Taylor M, Kirchner HL, Hoffman H. Frequency of voice problems among teachers and other occupations. J Voice. 1998;12: 480-488.

13. Kooijman PG, de Jong FI, Thomas G, Huinck W, Donders R, Graamans K, Schutte HK. Risk factors for voice problems in teachers. Folia Phoniatr Logop. 2006;58:159-174.

14. Thibeault SL, Merrill RM, Roy N, Gray SD, Smith EM. Occupational risk factors associated with voice disorders among teachers. Ann Epidemiol. 2004;14:786-792.

15. Verdolini K, Ramig LO. Review: occupational risks for voice problems. Logoped Phoniatr Vocol. 2001;26:37-46.

16. Nerriere E, Vercambre MN, Gilbert F, Kovess-Masfety V. Voice disorders and mental health in teachers: a cross-sectional nationwide study. $B M C$ Public Health. 2009;9:370.

17. Wewers ME, Lowe NK. A critical review of visual analogue scales in the measurement of clinical phenomena. Res Nurs Health. 1990;13: 227-236.

18. Mattiske JA, Oates JM, Greenwood KM. Vocal problems among teachers: a review of prevalence, causes, prevention, and treatment. J Voice. 1998;12: 489-499.

19. Roy N. Functional dysphonia. Curr Opin Otolaryngol Head Neck Surg. 2003;11:144-148.

20. Herrington-Hall BL, Lee L, Stemple JC, Niemi KR, McHone MM. Description of laryngeal pathologies by age, sex, and occupation in a treatment-seeking sample. J Speech Hear Disord. 1988;53:57-64.

21. Van Houtte E, Van Lierde K, D'Haeseleer E, Claeys S. The prevalence of laryngeal pathology in a treatment-seeking population with dysphonia. Laryngoscope. 2009;120:306-312.

22. Koufman JA, Blalock PD. Vocal fatigue and dysphonia in the professional voice user: Bogart-Bacall syndrome. Laryngoscope. 1988;98:493-498.

23. Welham NV, Maclagan MA. Vocal fatigue: current knowledge and future directions. J Voice. 2003;17:21-30.

24. Chen SH, Chiang SC, Chung YM, Hsiao LC, Hsiao TY. Risk factors and effects of voice problems for teachers. J Voice. 2010;24:183-190.

25. Belgian Statistics of Education. Available at: http://www.ond.vlaanderen. be/onderwijsstatistieken/. Last accessed April 15, 2010.

26. Pasa G, Oates J, Dacakis G. The relative effectiveness of vocal hygiene training and vocal function exercises in preventing voice disorders in primary school teachers. Logoped Phoniatr Vocol. 2007;32:128-140.

27. Gillivan-Murphy P, Drinnan MJ, O’Dwyer TP, Ridha H, Carding P. The effectiveness of a voice treatment approach for teachers with selfreported voice problems. J Voice. 2006;20:423-431.

28. Bovo R, Galceran M, Petruccelli J, Hatzopoulos S. Vocal problems among teachers: evaluation of a preventive voice program. J Voice. 2007;21: $705-722$. 